\title{
СИНТЕЗ МАГНЕТРОННЫМ РАСПЫЛЕНИЕМ И СТРУКТУРА ТОНКИХ ПЛЕНОК АРСЕНИДА КАДМИЯ
}

\author{
(C) 2019 г. А. В. Кочура ${ }^{1}$, В. С. Захвалинский ${ }^{2}$, Зо Хтет Аунг ${ }^{1}$, А. И. Риль ${ }^{3}$ *, \\ Е. А. Пилюк ${ }^{2}$, А. П. Кузьменко ${ }^{1}$, Б. А. Аронзон ${ }^{4,5}$, С. Ф. Маренкин ${ }^{3,6}$ \\ ${ }^{1}$ Юго-Западный государственный университет, ул. 50 лет Октября, 94, Курск, 305040 Россия \\ ${ }^{2}$ Белгородский государственный национальный исследовательский университет, \\ ул. Победы, 85, Белгород, 308015 Россия \\ ${ }^{3}$ Институт общей и неорганической химии им. Н.С. Курнакова Российской академии наук, \\ Ленинский пр., 31, Москва, 119991 Россия \\ ${ }^{4}$ Физический институт им. П.Н. Лебедева Российской академии наук, \\ Ленинский пр., 53, Москва, 119991 Россия \\ ${ }^{5}$ Национальный исследовательский центр “Курчатовский институт”, \\ пл. Академика Курчатова, 1, Москва, 123182 Россия \\ ${ }^{6}$ Национальный исследовательский технологический университет “МИСиС”, \\ Ленинский пр., 4, Москва, 119991 Россия \\ *e-mail: ril_alexey@mail.ru \\ Поступила в редакцию 22.02.2019 г. \\ После доработки 19.04.2019 г. \\ Принята к публикации 22.04.2019 г.
}

\begin{abstract}
Методом магнетронного распыления синтезированы тонкие ( 50 нм) пленки арсенида кадмия на подложках монокристаллического кремния и лейкосапфира. Методами РФА, СЭМ, АСМ и КРС установлено, что состав пленок соответствовал стехиометрии $\mathrm{Cd}_{3} \mathrm{As}_{2}$. Пленки кроме фазы $\alpha-\mathrm{Cd}_{3} \mathrm{As}_{2}$ содержали незначительное количество фазы $\alpha^{\prime}-\mathrm{Cd}_{3} \mathrm{As}_{2}$. При отжиге $520 \mathrm{~K}$ наблюдалась рекристаллизация с образованием текстурированных пленок с осью [112] на подложках из монокристаллического кремния. Области когерентного рассеяния в отожженных пленках, рассчитанные по уравнению Дебая-Шеррера, составили 30 нм.
\end{abstract}

Ключевые слова: тонкие пленки, магнетронное распыление, арсенид кадмия, удельное электросопротивление, отрицательное магнетосопротивление, структурный фазовый переход

DOI: $10.1134 / \mathrm{S} 0002337 \mathrm{X} 19090057$

\section{ВВЕДЕНИЕ}

Вешества, в которых энергетический спектр электронов содержит состояния, топологически защищенные в $k$-пространстве, обладают рядом замечательных свойств, таких как аномально высокие подвижность носителей заряда и проводимость, квантовые эффекта Холла и магнитоэлектрический эффект, а также связанными с ними киральными эффектами. За последнее десятилетие было обнаружено несколько десятков веществ с топологическими состояниями [1]. Среди этих материалов узкозонный полупроводник арсенид кадмия $\left(\mathrm{Cd}_{3} \mathrm{As}_{2}\right)$ с инвертированным строением энергетических зон и наивысшей среди неструктурированных полупроводников и полуметаллов подвижностью носителей заряда (до $10 \mathrm{~m}^{2} /(\mathrm{Bc})$ ) выделяется химической стабильностью, низкой токсичностью и хорошей технологичностью, заключающейся в наличии достаточно прорабо- танных методик его синтеза относительно недорогими методами [2]. Недавно по результатам теоретических [3] и экспериментальных [4, 5] исследований было установлено, что $\mathrm{Cd}_{3} \mathrm{As}_{2}$ относится к особому классу топологических изоляторов - дираковским полуметаллам, в которых носители заряда - дираковские фермионы - имеют нулевую эффективную массу и подчиняются релятивистским законам движения. Подобные системы рассматриваются как некий аналог трехмерного графена, а потому представляют значительный интерес с точки зрения как фундаментальной науки, так и потенциальных приложений.

Так, в монокристаллах $\mathrm{Cd}_{3} \mathrm{As}_{2}$ недавно были экспериментально обнаружены: наличие осцилляций Шубникова-де Гааза [5], гигантское линейное магнетосопротивление [6, 7], генерация фото-ЭДС на контакте металл-нанокристалл $\mathrm{Cd}_{3} \mathrm{As}_{2}$ [8], нетривиальный фотоэлектромагнит- 
ный эффект [9]. Крайне высокие значения подвижностей носителей заряда в $\mathrm{Cd}_{3} \mathrm{As}_{2}$, а также сверхмалое время отклика (6.9 пс) на падающее электромагнитное излучение [10] делают этот материал перспективным для использования в различных электронных устройствах, в том числе работающих в терагерцевом диапазоне [10, 11], а в работе [12] предсказана возможность создания высокоэффективного термоионного генератора на основе $\mathrm{Cd}_{3} \mathrm{As}_{2}$. Недавно была продемонстрирована высокая перспективность применения гетероструктур $\mathrm{Cd}_{3} \mathrm{As}_{2} /$ пентацен в качестве высокочувствительных широкодиапазонных (0.45-10.6 мкм) приемников оптического излучения, функционирующих при комнатной температуре [13], и $\mathrm{Cd}_{3} \mathrm{As}_{2}$ /графен - в устройствах спинтроники [14].

Выращенные различными методами пленки $\mathrm{Cd}_{3} \mathrm{As}_{2}$ и твердые растворы на его основе имели разную структуру: аморфную [15, 16], поликристаллическую [17-19] и монокристаллическую $[20,21]$. Недавно в высококачественных эпитаксиальных пленках $\mathrm{Cd}_{3} \mathrm{As}_{2}$ были обнаружены эффекты, связанные с наличием топологических состояний дираковского полуметалла [22-24]. Проблема получения таких пленок заключается в достаточно сильной зависимости их структуры и состава от условий напыления, например, от температуры подложки и скорости испарения мишени при использовании методов термического и лазерного испарения [16-18, 25].

В настоящей работе для напыления пленок $\mathrm{Cd}_{3} \mathrm{As}_{2}$ был применен магнетронный метод, поскольку он отличается достаточно равномерным распылением различных атомов мишени и слабой зависимостью процесса роста пленки от разницы давления их паров. В литературе нет сведений о получении пленок и структур на основе арсенида кадмия подобным методом.

\section{ЭКСПЕРИМЕНТАЛЬНАЯ ЧАСТЬ}

Тонкие пленки арсенида кадмия были получены методом высокочастотного магнетронного нереактивного напыления в атмосфере аргона. Мишень изготавливалась из предварительно синтезированных монокристаллов $\mathrm{Cd}_{3} \mathrm{As}_{2}$ малых размеров (не более 3 мм). Синтез таких кристаллов осуществлялся в два этапа. На первом этапе использовалось прямое сплавление исходных компонентов при температуре, на 100 К превышающей температуру плавления $\mathrm{Cd}_{3} \mathrm{As}_{2}\left(T_{\text {пл }}=994 \mathrm{~K}\right)$ [26]. Навески особо чистых порошков Cd (99.999\%) и As (99.99\%), взятых в стехиометрическом соотношении, помещались в графитизированные кварцевые ампулы, откаченные до давлений $p<$ $<0.01$ Па. Длительность синтеза составляла 10 ч с последующим медленным охлаждением в градиенте печи до комнатной температуры. На втором этапе полученный материал подвергался сублимации в вакууме. Он помещался в двойную кварцевую ампулу (внешняя ампула служила вакуумным чехлом, предотвращающим окисление материала в случае повреждения внутренней ампулы при охлаждении), вакуумировался и подвергался перегонке в паровой фазе в горизонтальной двухзонной печи. Температура в зоне испарения составляла $945 \mathrm{~K}$, а в зоне осаждения 773 К. В зоне осаждения происходил рост монокристаллов, из которых были отобраны тригональные кристаллы, имеющие характерную для микрокристаллов полиморфной модификации $\alpha-\mathrm{Cd}_{3} \mathrm{As}_{2}$ (пр. гр. $I 4_{1} c d$ ) форму в виде пирамид и призм [8].

Напыление тонких пленок $\mathrm{Cd}_{3} \mathrm{As}_{2}$ проводилось в вакуумной системе ВН-2000, оснащенной приставкой ВЧ-магнетронного нереактивного напыления. В качестве подложек использовались монокристаллические полированные ориентированные пластины кремния $p-\mathrm{Si}(100)$ ( $\rho=2$ Ом см) и лейкосапфира $\alpha-\mathrm{Al}_{2} \mathrm{O}_{3}(001)$. Следует отметить, что кристаллографические плоскости (0001) $\alpha-\mathrm{Al}_{2} \mathrm{O}_{3}$ и (224) $\alpha-\mathrm{Cd}_{3} \mathrm{As}_{2}$ структурно близки - расхождение их усредненного межатомного (межузельного) расстояния $6 \%$ (4.75 и $4.49 \AA$ А̊ соответственно) [18], что является предпосылкой для получения ориентированных пленок. Для различных ориентаций такого совпадения кристаллической структуры $\mathrm{Si}$ и $\mathrm{Cd}_{3} \mathrm{As}_{2}$ не наблюдается, поэтому удаление аморфного слоя естественного оксида с подложек из $\mathrm{Si}$ перед напылением не проводилось. Всего были получены три группы пленок $\mathrm{Cd}_{3} \mathrm{As}_{2}$ : без нагрева подложек, при нагреве подложек 520 К и отожженные в атмосфере аргона при температуре 520 K после напыления без нагрева подложек.

Рентгенофазовый анализ (РФА) пленок был выполнен с помощью рентгеновского дифрактометра GBC EMМА (излучение $\mathrm{Cu} K_{\alpha}, \lambda=1.5401 \AA$ ) при комнатной температуре.

Для исследования структуры образцов, их состава и распределения элементов по поверхности использовался сканирующий электронный микроскоп (СЭМ) JSM-6610LV (JEOL) с приставкой для энергодисперсионной рентгеновской спектроскопии (ЭДРС) X-Max ${ }^{\mathrm{N}}$ (Oxford Instruments). При съемке применялись детекторы вторичных и обратно рассеянных электронов.

Спектры комбинационного рассеяния света (KPC) исследуемых пленок были измерены при комнатной температуре с помощью конфокального спектрометра KPC OmegaScope ${ }^{\mathrm{TM}}$ (AIST-NT Inc.) с длиной волны лазерного излучения 532 нм, мощностью 50 мВт и размером пятна сфокусированного света на поверхности образца около 500 нм. Спектральное разрешение прибора составляло $0.8 \mathrm{~cm}^{-1}$. 


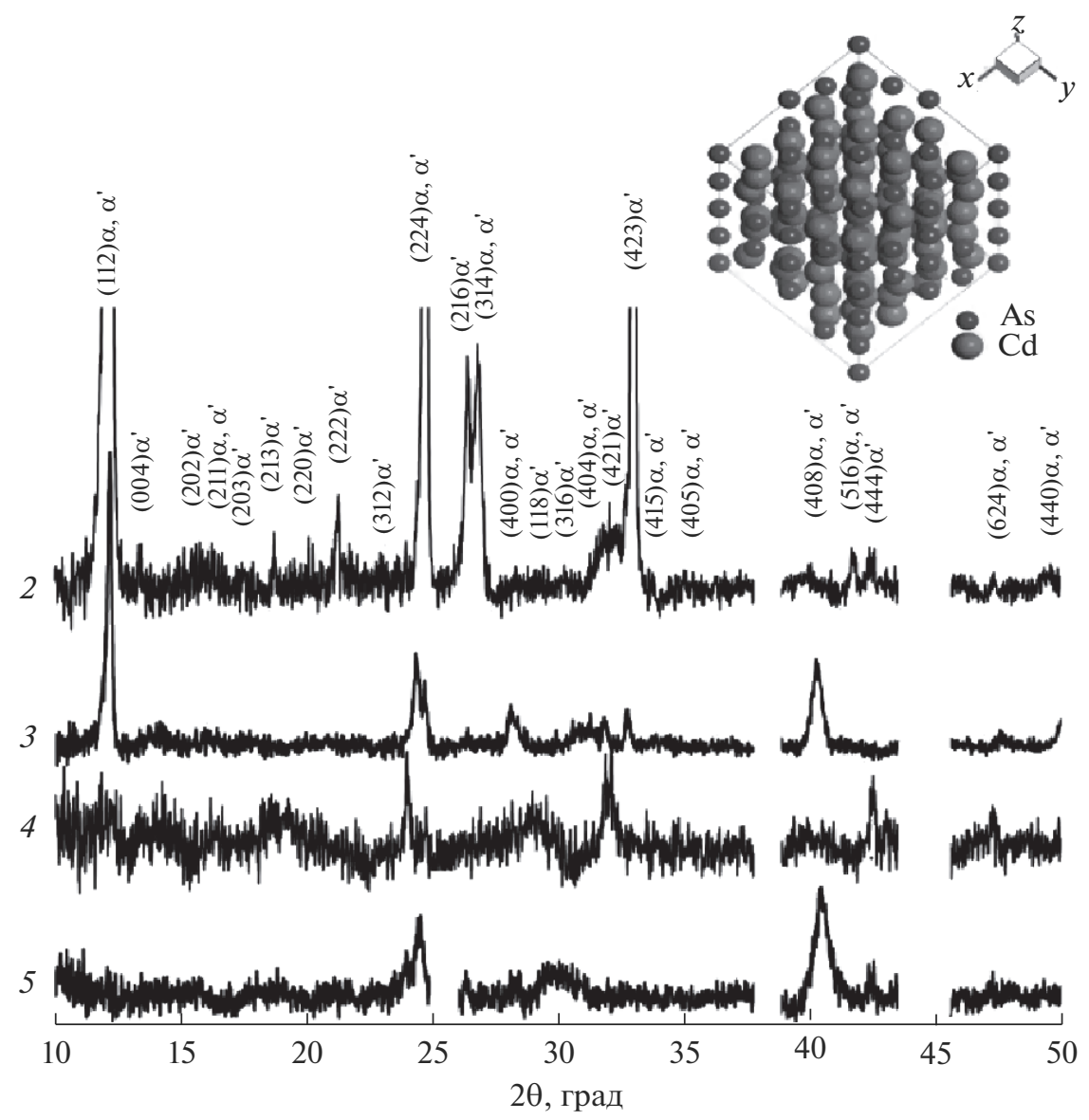

Рис. 1. Дифрактограммы тонких магнетронных пленок $\mathrm{Cd}_{3} \mathrm{As}_{2}$ (2-5); номера кривых соответствуют номерам образцов из табл. 1 ; дифракционные пики пленки 2 проиндексированы для двух полиморфных модификаций арсенида кадмия $\left(\alpha\right.$ и $\left.\alpha^{\prime}\right)$; на вставке представлена кристаллическая решетки $\alpha-\mathrm{Cd}_{3} \mathrm{As}_{2}$ в направлении преимущественной оси текстуры [112] пленок 2 и 3 (с дифрактограмм пленок удалены участки, содержащие дифракционные пики алюминия - материала держателя, а для образца 5 дифракционный пик подложки $\alpha-\mathrm{Al}_{2} \mathrm{O}_{3}$ ).

\section{РЕЗУЛЬТАТЫ И ИХ ОБСУЖДЕНИЕ}

Типичные дифрактограммы пленок $\mathrm{Cd}_{3} \mathrm{As}_{2}$ на различных подложках показаны на рис. 1. Проанализировать их удается, если предположить сосуществование в пленках двух полиморфных модификаций арсенида кадмия. Для пленки 2 для некоторых пиков указаны индексы в соответствии с дифракцией на кристаллах $\alpha-\mathrm{Cd}_{3} \mathrm{As}_{2}$ (пр. гр. $I 4_{1} c d$ ) и $\alpha^{\prime}-\mathrm{Cd}_{3} \mathrm{As}_{2}$ (пр. гр. $\left.P 4_{2} / n b c\right)$, полученные по данным базы ICSD [27] с помощью программы Powder Cell [28]. Параметры кристаллической решетки образцов и особенности напыления пленок приведены в табл. 1 .

Параметры решетки порошка мишени (образец 1) практически совпадают с табличными результатами для $\alpha-\mathrm{Cd}_{3} \mathrm{As}_{2}$. Дифрактограмма образ-

Таблица 1. Параметры кристаллической решетки пленок $\alpha-\mathrm{Cd}_{3} \mathrm{As}_{2}$ и порошка исходной мишени

\begin{tabular}{c|l|c|c|c}
\hline \multirow{2}{*}{$\begin{array}{c}\text { Номер } \\
\text { образца }\end{array}$} & \multicolumn{1}{|c|}{ Образец } & \multicolumn{2}{|c|}{ Параметры кристаллической решетки, А̊ } & \multirow{2}{*}{ ОКР } \\
\cline { 3 - 4 } & & $a$ & $c$ & $L$, нм \\
\hline 1 & Порошок мишени & 12.62 & 25.38 & - \\
2 & Пленка на нагретой подложке $\mathrm{Si}$ & 12.69 & 25.38 & 31 \\
3 & Отожженная пленка на подложке $\mathrm{Si}$ & 12.66 & 25.38 & 28 \\
4 & Пленка на подложке $\mathrm{Si}$ & 12.77 & 25.58 & - \\
5 & Отожженная пленка на подложке $\alpha-\mathrm{Al}_{2} \mathrm{O}_{3}$ & 12.59 & 25.38 & 35 \\
\hline
\end{tabular}


(a)

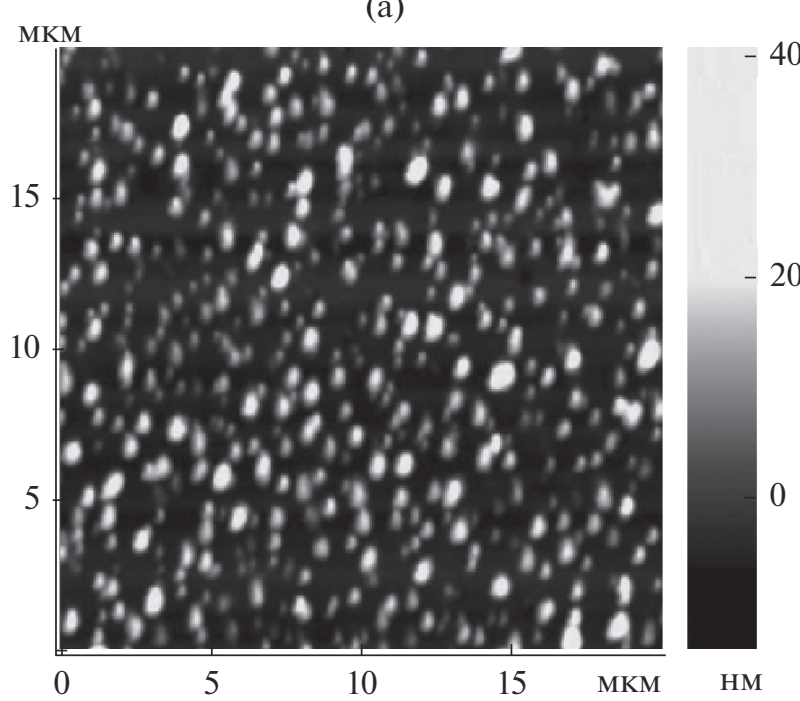

(B)

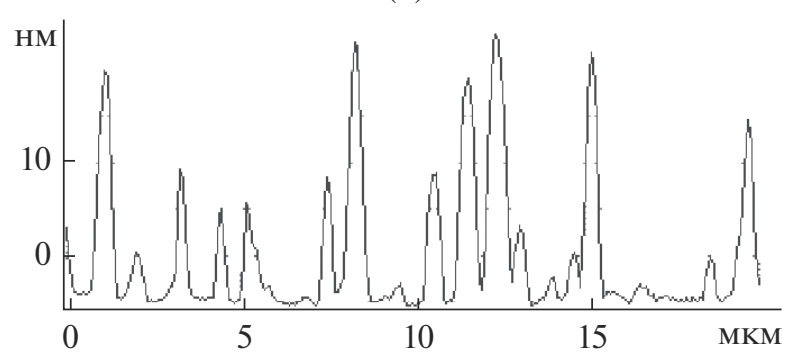

(д)

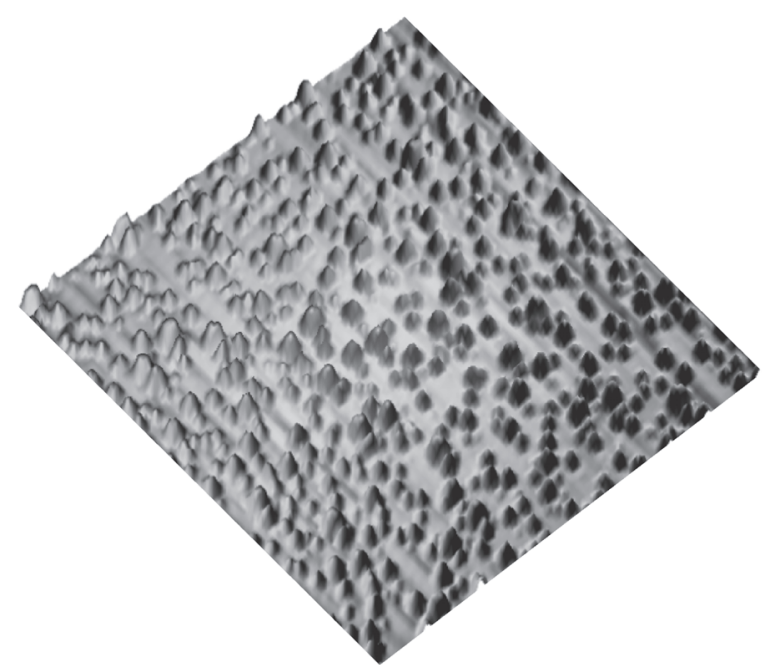

(б)



(г)



(e)

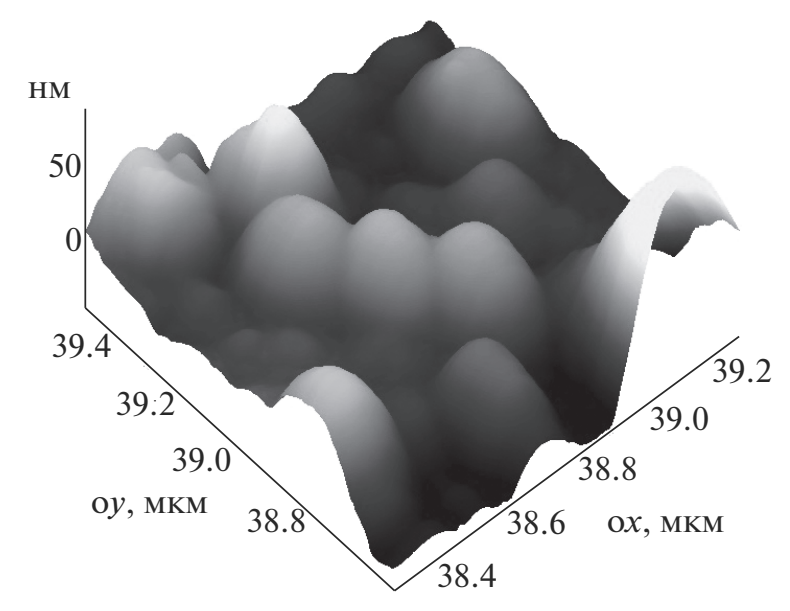

Рис. 2. СЗМ пленки 2 в центре (а) и около края (б); рельефы (в) и (г) от центральных частей изображений (а) и (б) соответственно представлены для оценки размеров гранул и толщины пленки; для наглядности приведены $3 D$-изображения гранулированной структуры пленок на различных масштабах: $10 \times 10$ мкм $^{2}$ (д) и $1 \times 1$ мкм ${ }^{2}(\mathrm{e})$.

ца 4 отличается низкой относительной интенсивностью, уширением дифракционных линий; параметры его решетки примерно на $1 \%$ больше величин $a$ и $c$ мишени. Это говорит о высокой дефектности кристаллической структуры пленки, напыленной на неподогреваемую подложку.
При отжиге и при напылении на подогреваемую подложку степень кристалличности пленок увеличивается, особенно при использовании $\mathrm{Si}$ в качестве подложки (образцы 2 и 3): параметры решетки уменьшаются и приближаются к табличным значениям, проявляются наиболее интен- 


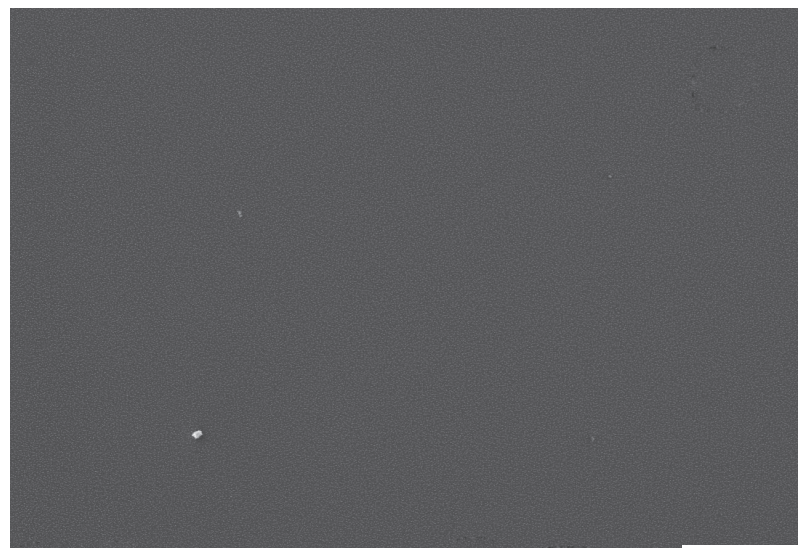

(a) 50 MKM
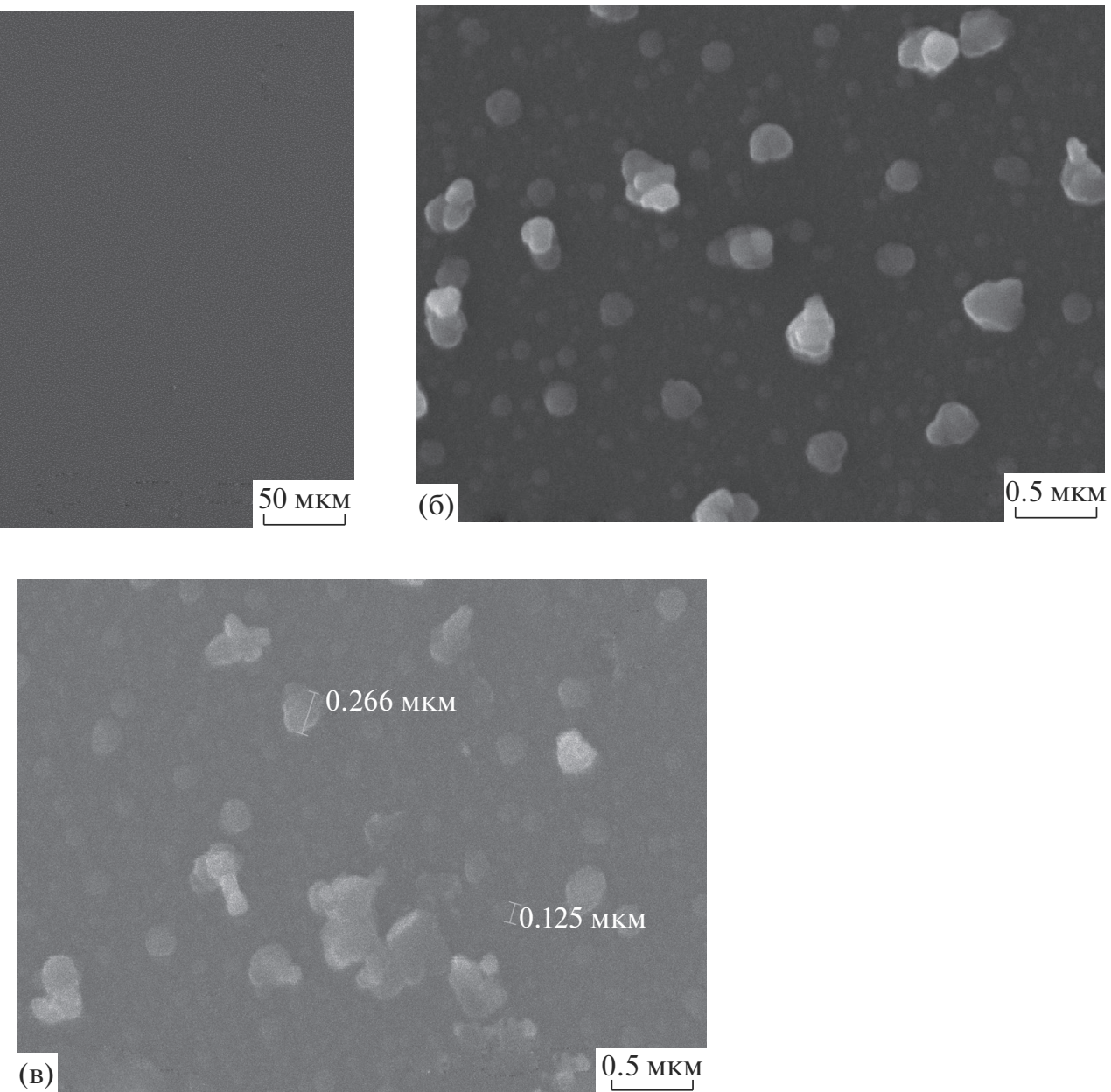

As $K_{\alpha 1}$

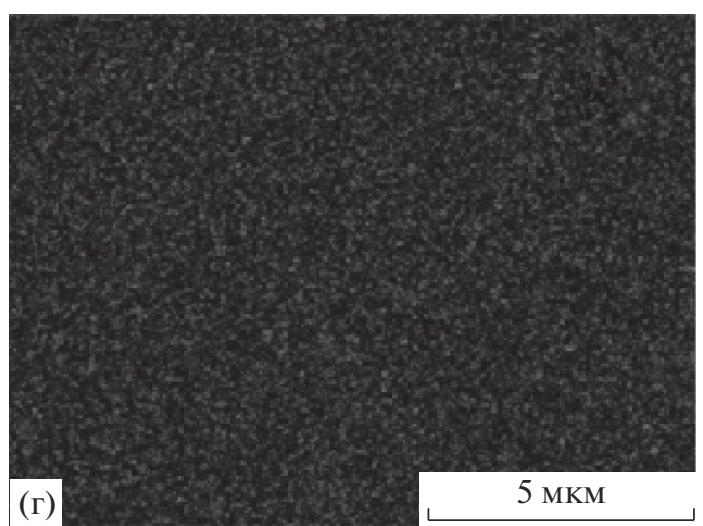

$\mathrm{Cd} K_{\alpha 1}$

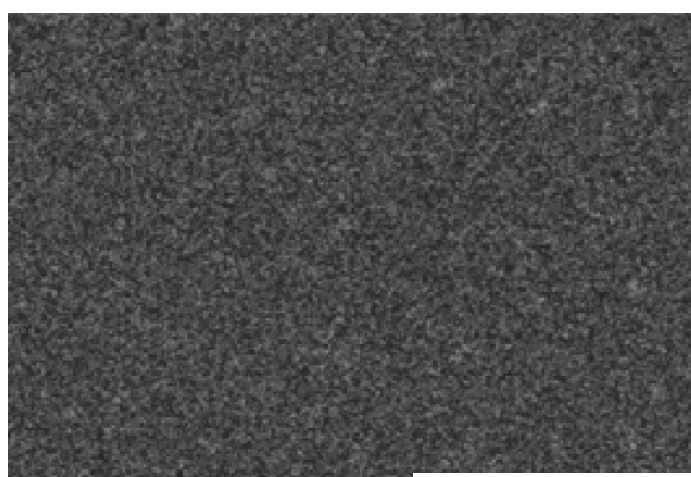

(д)

Рис. 3. СЭМ-изображения неотожженной пленки $4(\mathrm{a}$, б) и отожженной пленки 3 (в); г и д - карты распределения Аs и $\mathrm{Cd}$ по участку поверхности пленки 4, полученные методом ЭДРС.

сивные пики. На дифрактограммах пленок 2 и 3 самой интенсивной является линия 112, практически не проявляющийся в порошковой дифрактограмме материала мишени, что говорит о сильной рекристаллизации во время отжига, приводя- щей к текстурированию пленки с осью [112]. По уширению дифракционных линий по уравнению Дебая-Шеррера можно оценить область когерентного рассеяния (ОКР) рентгеновского излучения, которая сопоставима со средним размером 


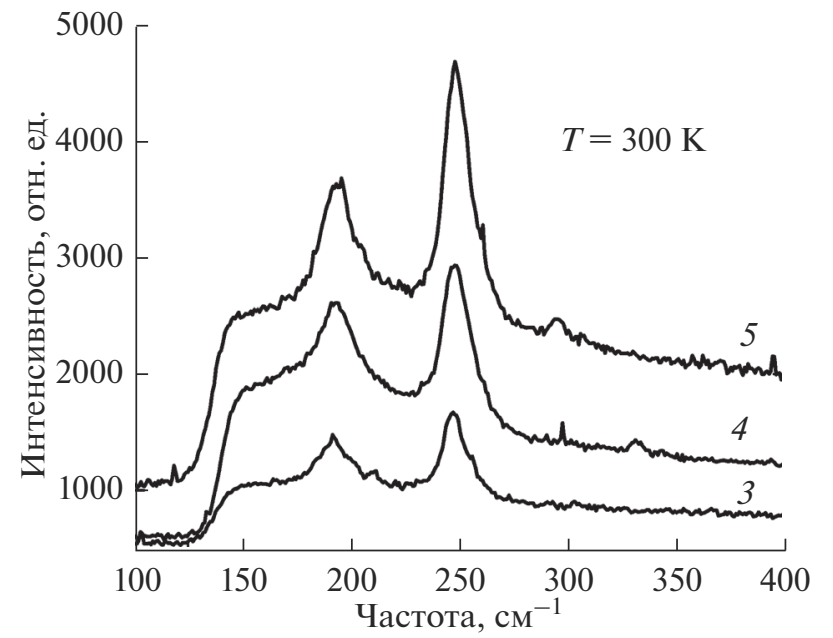

Рис. 4. Спектры КРС тонких магнетронных пленок $\mathrm{Cd}_{3} \mathrm{As}_{2}$ (3-5); номера кривых соответствуют номерам образцов из табл. 1 .

кристаллитов: $L=0.9 \lambda /(\beta \cos \theta)$, где $\lambda=0.1541 \mathrm{Hм,}$ $\beta$ - ширина линии (в радианах) на ее полувысоте, $\theta$ - угол дифракции. Полученные значения приведены в табл. 1.

Сканирующая зондовая микроскопия (С3М) (рис. 2) показывает, что пленки являются сплошными с гранулированной структурой поверхности с высотой гранул в несколько раз меньше, чем толщина пленки. Латеральный размер гранул составлял величину до 1 мкм. После отжига топология поверхности практически не изменяется.

По СЭМ-изображениям видно, что пленки при малых увеличениях (десятки микрометров) практически однородны (рис. 3a), но при больших увеличениях заметна их гранулированная структуpa (рис. 3б), причем после отжига структура поверхности практически не изменяется (рис. 3в). По распределению элементов пленки в пределах области измерений они имели гомогенную структуру, а отношение $\mathrm{Cd}$ : Аs близко к стехиометрическому $3: 2$.

Исследование колебаний кристаллической решетки с помощью спектров КРС в дальней ИКобласти (рис. 4) подтверждает, что пленки по составу являются арсенидом кадмия.

В работе [29] показано, что большая часть основных комбинационно - активных мод $\alpha-\mathrm{Cd}_{3} \mathrm{As}_{2}$

$$
\Gamma^{R}=26 A_{1}+27 B_{1}+27 B_{2}+65 E
$$

располагается в области $\omega<100 \mathrm{~cm}^{-1}$. В измеренной нами области спектра $\left(\omega>150 \mathrm{~cm}^{-1}\right)$ при комнатной температуре могут наблюдаться два широких пика - около 196 и $247 \mathrm{~cm}^{-1}$, природа которых не связана с классическим механизмом неупругого рассеяния света. Однако их часто используют для характеризации наноструктур, со- держащих $\mathrm{Cd}_{3} \mathrm{As}_{2}$ [30-32]. Появление этих пиков обусловлено особенностями зонной структуры $\mathrm{Cd}_{3} \mathrm{As}_{2}$ и объясняется с помощью трехзонной модели с учетом как межзонных, так и внутризонных переходов [29]. Похожий вид спектра наблюдался у $\alpha "$-полиморфной модификации $\mathrm{Cd}_{3} \mathrm{As}_{2}$ : в области $\omega>100 \mathrm{~cm}^{-1}$ присутствуют только два пика, расположенные вблизи 189 и $244.5 \mathrm{~cm}^{-1}$ [33-35]. Спектры KРC $\mathrm{CdAs}_{2}$ - наиболее часто встречающегося преципитата к арсениду кадмия - немного сложнее [31]: при комнатной температуре они содержат четыре пика: 194, 223, 248 и $260 \mathrm{~cm}^{-1}$ при $\omega>130 \mathrm{~cm}^{-1}$.

Для пленки 3 сигнал КРС был слабее ввиду ее малой толщины (около 50 нм). В то время как для образцов 4 и 5 с толщиной около 100 нм наблюдается картина, типичная для арсенида кадмия. Влияние возможных включений чистого кадмия в пленках не обнаруживается, поскольку кадмий обладает металлической проводимостью, что могло отразиться в виде сильного снижения интенсивности регистрируемого излучения и появления плазмонного плеча, возникающего в материалах с высокой концентрацией носителей заряда. Присутствие диарсенида кадмия по характерным фононам также не обнаруживается. При измерении спектров КРС для пленки 4 в разных поляризациях было обнаружено изменение в соотношении высот пиков, что говорит о наличии текстуры у пленки, т.е. ее частичной ориентации.

\section{ЗАКЛЮЧЕНИЕ}

Синтезированы пленки арсенида кадмия толщиной $\sim 50$ нм на кремниевых и лейко-сапфировых подложках. Установлено, что состав пленок соответствовал стехиометрии $\mathrm{Cd}_{3} \mathrm{As}_{2}$. Пленки состояли в основном из фазы $\alpha-\mathrm{Cd}_{3} \mathrm{As}_{2}$, в них также присутствовали следы фазы $\alpha-\mathrm{Cd}_{3} \mathrm{As}_{2}$. В пленках, выращенных на нагретых подложках, и пленках, подвергнутых термическому отжигу, происходил процесс рекристаллизации и наблюдалась текстура, особенно на кремниевых подложках с осью направленности кристаллитов [112], размер которых составлял $\sim 30 \mathrm{Hм}$.

\section{БЛАГОДАРНОСТЬ}

Работа выполнена при поддержке Российского научного фонда (грант № 17-12-01345). Структурные исследования были выполнены в рамках государственного задания ИОНХ РАН в области фундаментальных научных исследований при частичной поддержке программы Президиума РАН I.35 "Научные основы создания новых функциональных материалов” и частично поддержаны Министерством высшего образования и науки РФ (грант № 16.2814.2017/ПЧ). 


\section{СПИСОК ЛИТЕРАТУРЫ.}

1. Armitage N.P., Mele E.J., Vishwanath A. Weyl and Dirac Semimetals in Three-Dimensional Solids // Rev. Mod. Phys. 2018. V. 90. 015001. https://doi.org/10.1103/RevModPhys.90.015001

2. Лазарев В.Б. Полупроводниковые соединения группы $\mathrm{A}^{\mathrm{II}} \mathrm{B}^{\mathrm{V}}$. М.: Наука, 1978. 255 c.

3. Wang Z., Weng H., Wu Q., Dai X., Fang Z. Three-Dimensional Dirac Semimetal and Quantum Transport in $\mathrm{Cd}_{3} \mathrm{As}_{2} / /$ Phys. Rev. B 2013. V. 88. 125427. https://doi.org/10.1103/PhysRevB.88.125427

4. Borisenko S., Gibson Q., Evtushinsky D., Zabolotnyy V., Buchner B., Cava R.J. Experimental Realization of a Three-Dimensional Dirac Semimetal // Phys. Rev. Lett. 2014. V.113. № 2. 027603. https://doi.org/10.1103/PhysRevLett.113.027603

5. He L.P., Hong X.C., Dong J.K., Pan J., Zhang Z., Zhang J., Li S.Y. Quantum Transport Evidence for the Three-Dimensional Dirac Semimetal Phase in $\mathrm{Cd}_{3} \mathrm{As}_{2} / /$ Phys. Rev. Lett. 2014. V. 113. 246402.

https://doi.org/10.1103/PhysRevLett.113.246402

6. Feng J., Pang Y., Wu D., Wang Z., Weng H., Li J., Dai X., Fang $Z$., Shi $Y$., Lu L. Large Linear Magnetoresistance in Dirac Semimetal $\mathrm{Cd}_{3} \mathrm{As}_{2}$ with Fermi Surfaces Close to the Dirac Points // Phys. Rev. B. 2015. V. 92. 081306(R). https://doi.org/10.1103/PhysRevB.92.081306

7. Zhang K., Pan H., Zhang M., Wei Z., Gao M., Song F., Wang $X$., Zhang $R$. Controllable synthesis and magnetotransport properties of $\mathrm{Cd}_{3} \mathrm{As}_{2}$ Dirac semimetal nanostructures // RSC Adv. 2017. V. 7. P. 1768917696. https://doi.org/10.1039/C7RA02847D

8. Li C.-Z., Zhu R., Ke X., Zhang J.-M., Wang L.-X., Zhang L., Liao Z.-M., Yu. D.-P. Synthesis and Photovoltaic Properties of $\mathrm{Cd}_{3} \mathrm{As}_{2}$ Faceted Nanoplates and Nano-Octahedrons // Cryst. Growth Design. 2015. V. 5. № 7. 3264-3270.

https://doi.org/10.1021/acs.cgd.5b00399

9. Galeeva A.V., Krylov I.V., Drozdov K.A., Knjazev A.F., Kochura A.V., Kuzmenko A.P., Zakhvalinskii V.S., Danilov S.N., Ryabova L.I., Khokhlov D.R. Electron Energy Relaxation under Terahertz Excitation in $\left(\mathrm{Cd}_{1-x} \mathrm{Zn}_{x}\right)_{3} \mathrm{As}_{2}$ Dirac semimetals // Belstein J. Nanotechnol. 2017. V. 8. P. 167-171. https://doi.org/10.3762/bjnano.8.17

10. Wang Q., Li C.-Z., Ge S., Li J.-G., LuW., Lai J., Liu X., Ma J., Yu D.-P., Liao Z.-M., Sun D. Ultrafast Broadband Photodetectors Based on Three-Dimensional Dirac Semimetal $\mathrm{Cd}_{3} \mathrm{As}_{2} / /$ Nano Lett. 2017. V. 17. № 2. P. 834-841. https://doi.org/10.1021/acs.nanolett.6b04084

11. Walowski J., Münzenberg M. Perspective: Ultrafast magnetism and THz Spintronics // J. Appl. Phys. 2016. V. 120. 140901 . https://doi.org/10.1063/1.4958846

12. Zhang $X$., Peng $W$., Su G., Su S., Chen J. Thermionic Energy Conversion Based on 3D Dirac Semimetals // J. Phys. D: Appl. Phys. 2018. V. 51. № 10. 405501. https://doi.org/10.1088/1361-6463/aad975

13. Yang M., Wang J., Han J., Ling J., Ji C., Kong X., Liu X., Huang Z., Gou J., Liu Z., Xiu F., Jiang Y. Enhanced Per- formance of Wideband Room Temperature Photodetector Based on $\mathrm{Cd}_{3} \mathrm{As}_{2}$ Thin Film/Pentacene Heterojunction // ASC Photonics. 2018. V.5. № 8. 34383435. https://doi.org/10.1021/acsphotonics.8b00727

14. Wu Y.F., Zhang L., Li C.Z., Zhang Z.S., Liu S., Liao Z.M., $Y u$ D. Dirac Semimetal Heterostructures: 3D $\mathrm{Cd}_{3} \mathrm{As}_{2}$ on 2D Graphene // Adv. Mater. 2018. V. 30. № 34. 1707547. https://doi.org/10.1002/adma.201707547

15. Jarzabek B., Weszka J., Cisowski J. Distribution of Electronic States in Amorphous Cd-As Thin Films on the Basis of Optical Measurements // J. Non-Cryst. Solids. 2004. V. 333. № 2. P. 206-211. https://doi.org/10.1016/j.jnoncrysol.2003.09.045

16. Dubowski J.J., Williams D.F. Pulsed Laser Evaporation of $\mathrm{Cd}_{3} \mathrm{As}_{2} / /$ Appl. Phys. Lett. 1984. V. 44. № 3. P. 339. https://doi.org/10.1063/1.94752

17. Dubowski J.J., Norman P., Sewell P.B., Williams D.F., Kròlicki F., Lewicki M. Cadmium Arsenide Films Prepared by Pulsed Laser Evaporation: Electrical Properties and lattice parameters // Thin Solid Films. 1987. V. 147. № 1. P. L51-L54. https://doi.org/10.1016/0040-6090(87)90047-2

18. Жалилов Н.С., Саныгин В.П., Квердаков А.М., Пашкова О.Н. Получение и свойства тонких пленок $\mathrm{Cd}_{3} \mathrm{As}_{2}$ и $\mathrm{Zn}_{3} \mathrm{P}_{2} / /$ Изв. АН СССР. Неорган. материалы. 1990. Т. 26. Вып. 9. С. 1975-1976.

19. Din M., Gould R.D. Van der Pauw Resistivity Measurements on Evaporated Thin Films Of Cadmium Arsenide, $\mathrm{Cd}_{3} \mathrm{As}_{2}$ // Appl. Surf. Sci. 2006. V. 252. № 15. P. 5508-5501. https://doi.org/0.1016/j.apsusc.2005.12.151

20. Nishihaya S., Uchida M., Nakazawa Y., Akiba K., Kriener M., Kozuka Y., Miyake A., Taguchi Y., Tokunaga M. Kawasaki $M$. Negative Magnetoresistance Suppressed through a Topological Phase Transition in $\left(\mathrm{Cd}_{1-x} \mathrm{Znx}\right)_{3} \mathrm{As}_{2}$ Thin Films // Phys. Rev. B. 2018. V. 97. № 24. 245103 https://doi.org/10.1103/PhysRevB.97.245103

21. Pawlikowski J.M., Sierański K., Szatkowski J. A New Method of Obtaining Crystalline $\mathrm{Cd}_{3} \mathrm{As}_{2}$ Films on Non-Crystalline Substrates // Thin Solid Films. 1975. V. 30. № 1. P. 99-102. https://doi.org/10.1016/0040-6090(75)90309-0

22. Yuan X., Cheng P., Zhang L., Zhang C., Wang J., Liu Y., Sun Q., Zhou P., Zhang D.W., Hu Z., Wan X., Yan H., Li Z., Xiu F. Direct Observation of Landau Level Resonance and Mass Generation in Dirac Semimetal $\mathrm{Cd}_{3} \mathrm{As}_{2}$ Thin Films // Nano Lett. 2017. V. 17. № 4. P. 2211-2219. https://doi.org/10.1021/acs.nanolett.6b04778

23. Schumann T., Galletti L., Kealhofer D.A., Kim H., Goyal M., Stemmer $S$. Observation of the Quantum Hall Effect in Confined Films of the Three-Dimensional Dirac Semimetal $\mathrm{Cd}_{3} \mathrm{As}_{2}$ // Phys. Rev. Lett. 2018. V. 120. № 1.016801 . https://doi.org/10.1103/PhysRevLett.120.016801

24. Galletti L., Schumann T., Shoron O.F., Goyal M., Kealhofer D.A., Kim H., Stemmer S. Two-Dimensional Dirac Fermions in Thin Films of $\mathrm{Cd}_{3} \mathrm{As}_{2}$ // Phys. Rev. B. 2018. V. 97. № 11. 115132 . https://doi.org/10.1103/PhysRevB.97.115132 
25. Zdanowicz L., Pocztowski G., Weclewicz C., Niedzwiedz N., Kwiecien T. Some Properties of Thin Amorphous $\mathrm{Cd}_{3} \mathrm{As}_{2}$ Films Related to Deposition Conditions // Thin Solid Films. 1976. V. 34. № 1. P. 161-164. https://doi.org/10.1016/0040-6090(76)90158-9

26. Arushanov E.K. Crystal Growth and Characterization of $\mathrm{II}^{3} \mathrm{~V}^{2}$ Compounds // Prog. Cryst. Growth Character. 1980. V. 3. P. 211. https://doi.org/10.1016/0146-3535(80)90020-9

27. Bergerhoff G., Brown I.D. Crystallographic Databases / Eds. Allen F.H. et al. Chester: International Union of Crystallography, 1987.

28. Kraus $W$., Nolze G. POWDER CELL - a Program for the Representation and Manipulation of Crystal Structures and Calculation of the Resulting X-ray Powder Patterns // J. Appl. Cryst. 1996. V. 29. P. 301-303. https://doi.org/10.1107/S0021889895014920

29. Weszka J., Renucc M.I., Zwick A. Some Aspects of Raman Scattering in $\mathrm{Cd}_{3} \mathrm{As}_{2}$ Single Crystals // Phys. Status Solidi (B). 1986. V. 133. P. 57. https://doi.org/10.1002/pssb.2221330106

30. Wei S., Lu J., Zhang W., Qian Y. Isostructural $\mathrm{Cd}_{3} \mathrm{E}_{2}$ $(\mathrm{E}=\mathrm{P}, \mathrm{As})$ Microcrystals Prepared via a Hydrothermal Route // Cryst. Growth Design. 2006. V. 6. № 4.
P. 849-853. https://doi.org/10.1021/cg049589u

31. Schönherr P., Hesjedal T. Structural properties and growth mechanism of $\mathrm{Cd}_{3} \mathrm{As}_{2}$ nanowires // Appl. Phys. Lett. 2015. V. 106. 013115. https://doi.org/10.1063/1.4905564

32. Cheng P., Zhang C., Liu Y., Yuan X., Song F., Sun Q., Zhou P., Zhang D.W., Xiu F. Thickness-Dependent Quantum Oscillations in $\mathrm{Cd}_{3} \mathrm{As}_{2}$ Thin Films // New J. Phys. 2016. V. 18. 083003. https://doi.org/10.1088/1367-2630/18/8/083003

33. Weszka J., Balkanski M., Raukhman A.M., Marenkin S.F. Raman Scattering and Lattice Vibrations in Tetragonal $\mathrm{CdAs}_{2}$ Crystals // Phys. Status Solidi (B). 1996. V. 194. P. 509 . https://doi.org/10.1002/pssb.2221940208

34. Маренкин С.Ф., Трухан В.М. Фосфиды, арсениды цинка и кадмия. Минск: Вараксин А.Н., 2010. 220 с.

35. Shchelkachev N.M., Yarzhemsky V.G. Influence of Crystal Structure and 3d Impurities on the Electronic Structure of the Topological Material Cd3As2// Inorg. Mater. 2018. V.54. № 11. P. 1093-1098. https://doi.org/10.1134/S0020168518110110. 